\title{
Psychological outcomes following the Hazelwood mine fire: A mixed methods study
}

Darryl Maybery ${ }^{1}$, Rebecca Jones ${ }^{1}$, Matthew Carroll ${ }^{2}$, Joanna F Dipnall ${ }^{3,4}$, Emily

Berger $^{5}$, Tim Campbell ${ }^{1,2}$, Alexander McFarlane ${ }^{6}$

\section{Corresponding author:}

Professor Darryl Maybery, Director of Research, Monash Rural Health, Monash University.

Monash Rural Health Warragul, West Gippsland Health Care Group, Cottage 13, Sargeant Street, Warragul, VIC 3820, Australia

darryl.maybery@monash.edu

Note. This is the original pre-print version of an article which is being submitted to independent peer review by an academic journal. The subsequent scientific manuscript may vary somewhat in findings or interpretation

\footnotetext{
${ }^{1}$ Monash Rural Health Warragul, Monash University, Warragul, Australia

${ }^{2}$ Monash Rural Health Churchill, Monash University, Churchill, Australia

${ }^{3}$ School of Public Health and Preventive Medicine, Monash University, Melbourne Australia

${ }^{4}$ IMPACT SRC, School of Medicine, Deakin University, Geelong, Australia

${ }^{5}$ Faculty of Education, Monash University, Clayton, Australia

${ }^{6}$ The Centre for Traumatic Stress Studies, The University of Adelaide, Australia
} 


\begin{abstract}
Objectives: This mixed method study assessed the psychological impacts of six weeks of exposure to smoke and ash from the 2014 Hazelwood mine fire in the Latrobe Valley in Victoria, Australia. The quantitative component compared residents from the most exposed community (Morwell) with those from a similar, but minimally-exposed, control community (Sale). Qualities of the experience were examined in interviews with Morwell residents.
\end{abstract}

Methods: A cross-sectional survey involved 3,091 Morwell and 960 Sale adults with multiple psychological measures was complimented by 26 interviews with Morwell residents.

Results: Morwell residents scored significantly higher than Sale residents on the primary outcome measure, the Impact of Event Scale - Revised (difference $=6.53 ; 95 \% \mathrm{CI}: 5.37,7.35, \mathrm{p}<0.001$ ), which measured the posttraumatic stress symptoms of intrusive rumination, hyperarousal and avoidance behaviour. Morwell residents also scored significantly higher on the Kessler 10-item general distress scale $($ difference $=1.69 ; 95 \% \mathrm{CI}: 1.05,2.33, \mathrm{p}<0.001)$. On average, the Hazelwood mine fire continued to generate moderate levels of participant distress more than two years after the event, however this ranged from no impact to more severe distress. This range of impact was also evident in the qualitative interviews, where intrusive thoughts were the most frequently reported symptom of posttraumatic stress. The interviews highlighted the increased vulnerability of people with pre-existing mental health concerns.

Conclusions: The finding that moderate distress was apparent in the community several years after an extended community-wide pollution event highlights the need for improving response to such events, including providing support to more vulnerable subgroups.

\title{
Key words
}

Posttraumatic stress disorder; disaster; bushfires; smoke exposure; Hazelwood coalmine fire 


\section{Introduction}

Early in 2014, two bushfires 'spotted' into an open-cut brown coal mine, adjacent to the Hazelwood Power Station in the Latrobe Valley in Victoria, Australia. The 3,138 hectare mine caught fire and burnt for six weeks (Teague, Catford, \& Petering, 2014), resulting in the nearby town of Morwell and other areas of the Latrobe Valley being covered in plumes of smoke and ash. Morwell residents experienced higher smoke concentration, particularly areas to the immediate north and northeast edges of the mine, with nearby townships experiencing lower concentrations of smoke (Emmerson, Reisen, Luhar, Williamson, \& Cope, 2016). An early report on the community impacts indicated heightened concern about the physical and mental health complications of the smoke, and perceived failures of the emergency response (Wood et al., 2015).

Australia has a long history of bushfires. The most recent being the Ash Wednesday and Black Saturday bushfires in 1983 and 2009 respectively (Bryant et al., 2014). The latter resulted in huge property loss and over 170 deaths, with approximately 15 percent of people reporting symptoms of posttraumatic stress disorder (PTSD) some three years afterwards (Bryant et al., 2014). McFarlane and colleagues (McFarlane, 1988; McFarlane, Clayer, \& Bookless, 1997) found 42 percent of people affected by the Ash Wednesday bushfires had heightened levels of distress one year later, almost double that in the general population $(23 \%)$.

In one of the few reports on the health impacts of coalmine fires, Melody and Johnston (2015) suggest that such fires differ to traditional bushfires in terms of air quality, with smouldering combustion and high concentrations of toxins potentially increasing the risk of resultant adverse health effects. The Hazelwood Mine Fire Inquiry reported a number of physical impacts for residents at the time of the fire, such as headaches, nausea and vomiting, chest pains, increased blood pressure, and shortness of breath (Teague et al., 2014). 
The psychological impacts of exposure to smoke from coalmine fires are even less well understood. The Hagersville tyre-fire in Ontario, Canada, shared similar characteristics to the current study with a fire burning for 17 days and smoke reported to have affected thousands of people. Interviews with residents indicated differing levels of concern relating to health risks from the smoke, ranging from "...great concern about contamination to mere annoyance with various inconveniences" (Baxter, Eyles, \& Willms, 1992, p.230). The Hagersville study found an age effect, with less impact on older people who had lived in the community for many years and higher impact on newer and younger residents with children.

Ho et al.'s (2014) report on the impacts for the general population following the forest fires in Indonesia in 2013 used the Impact of Event Scale - Revised (IES-R, Weiss \& Marmar, 1997) to quantify the level of psychological stress and found participants experienced mild psychological stress (mean total IES-R score=18.47, $S D=11.69$ ). However, Ho et al. used an online snowball sampling technique, which potentially biased results because of the possibility that highly impacted people, as well as younger and more educated people, may have been overrepresented. Notably, Ho et al. also measured the impact of the event as it was occurring rather than two years later, as in the current study.

\subsection{Study aims}

The current study employed a mixed method approach that aimed to:

1. Quantify the psychological impacts of exposure to the smoke event on Morwell adults using the Impact of Events Scale - Revised (IES-R) and several measures of mental health comparing them to the Sale control group; and

2. Examine the qualitative experiences of a subsample of Morwell adults to understand the mine fire in terms of the intrusion, avoidance and hyperarousal subscales of the IES-R.

This study provides evidence of the mental health impacts of smoke events on adults that is useful to health professionals and service providers in improving the management of psychological distress in at-risk communities. 


\section{Method}

The mixed design purposefully engages the strengths of quantitative in determining the magnitude and frequency of psychological impacts associated with the event and qualitative in exploring the qualities and meaning of the event impact for participants (Cresswell, 2014). The study was approved by the Monash Human Research Ethics Committee (project numbers CF15/872 and 9206).

\subsection{Quantitative component}

\subsubsection{Participants}

The Hazelwood Health Study (HHS) Adult Survey was conducted from 2016-2017 in Morwell and an area of Sale determined to be most sociodemographically comparable to Morwell. Eligible subjects were aged 18 years or older at the time of the mine fire and their contact details obtained from the Victorian electoral roll. The final sample comprised 3,091 adults from Morwell and 960 from Sale, representing participation rates of $34 \%$ and $23 \%$ respectively.

\subsubsection{Recruitment}

Recruitment procedures are described in detail in the first volume of analyses from the HHS Adult Survey (Abramson et al., 2017) and are summarised briefly here.

Methods used to recruit eligible residents from Morwell and Sale included direct-mailed invitation and reminder-packs, phone follow-up, media engagement, public events, flyers, posters, and survey packs available at public venues.

\subsubsection{Measures}

The larger survey was an extensive self-report health survey that participants completed by phone interview, online or on paper. The demographic and mental health components of the survey are outlined here.

Demographic items included gender, age, marital status, cultural background, education, and employment. Participants were asked if they had "ever been told by a doctor or psychologist that" they had depression, anxiety or PTSD, or any other mental health conditions. Participants who self- 
reported a mental health condition in their history were asked to estimate the year they were first diagnosed, so first diagnosis could be classified by whether it had occurred prior to, or after the fire. Current subjective level of distress associated with prior exposure to the smoke event was measured using the 22-item IES-R scale (Weiss \& Marmar, 1997), scored on a 0-4 scale (0:Not at all to 4:Extremely). Participants were instructed to focus on current distress associated with the 2014 mine fire: "During the past seven days, in regard to the mine fire event, how much were you distressed or bothered by these difficulties?" The IES-R scale includes subscales aligned with diagnostic criteria for PTSD (American Psychiatric Association, 2013): Intrusion (such as unwanted thoughts of the event; ranged 0-32); Avoidance (such as trying not to think about the event; ranged 0-32); and Hyperarousal (such as being jumpy and easily startled; ranged 0-24). The total IES-R score ranged from 0 to 88 , and reliability of the measure is presented in the results. A score-range of 24 to 32 (Asukai et al., 2002) was adopted as indicative of risk for developing PTSD, and a cut-off score of 33 or more (Creamer, Bell, \& Failla, 2003) as indicative of probable PTSD diagnosis.

The 10-item Kessler Psychological Distress Scale (K10, Kessler \& Mroczek, 1994; Kessler et al., 2003) is used extensively as a population screener for psychological distress. Items relate to the level of anxiety and depression experienced in the past four weeks, scored on a 1-5 scale (1:None of the time to 5:All of the time). Items were summed to generate a total K10 score (ranged 10-50).

The survey utilised a list of 11 stressful life events extracted from the PTSD module of the Composite International Diagnostic Interview, Version 2.1. (Robins et al., 1988). This measured participant exposure to major stressful events other than the coalmine fire, and included exposure to combat, a life-threatening accident, rape or physical attack, or any other extremely stressful or upsetting event that happened to a significant other. The number of major stressful events for each participant was tallied and then grouped into three categories: none, one or two, and three or more. 


\subsubsection{Statistical Analysis}

For the purposes of this research, all demographic categorical variables were collapsed into two groups (see Table 1) for comparison against the smaller qualitative group. The ordinal Index of Relative Socio-economic Advantage and Disadvantage (IRSAD) scores were downloaded from the Australian Bureau of Statistics (Australian Bureau of Statistics, 2013). A high IRSAD score indicates greater advantage in general.

Cronbach's alpha was calculated on the raw standardised item scale data to assess the internal reliability of the scales. Pearson's test of independence was used to compare the two locations for categorical variables and the complex survey design was accounted for by using the Rao and Scott correction $(1981 ; 1984)$. Mean estimation was utilised for the continuous variables and linearised standard errors were calculated based on a first-order Taylor series linear approximation (Wolter, 2007).

Missing data across the mental health scales were analysed, with the largest proportion of missing data being $5.8 \%$ for the IES-R Total score. Little's test for missing completely at random was significant across the IES-R and K10 items ( $<<0.001)$, confirming the need for multiple imputation (Little, 1988, 1995). Multiple imputation by chained equations was performed to create 20 imputation sets (Royston \& White, 2011). For each item in both scales, the imputation equation was reduced to only those items within the sub-scale, and then only the sum scores for the other sub-scales. Due to the presence of covariate-dependent missingness, age and gender were also included in the imputation process. The mental health conditions of depression, anxiety, and any mental health condition were included as covariates in the imputation process. Estimation using the multiple imputations produced pooled estimates of the IES-R, K10, and prior stressful life event measures. Using Rubin's rules (1987), pooled mean estimation scores across the imputation sets were generated for the IES-R and K10 scores across the groups within the demographics, mental health and prior stressful life events measures. Missing data for self-reported conditions ranged from $0.44 \%$ for 'any' mental health conditions to $1.36 \%$ for depression, with multiple imputation by 
chained equations again used. Log Poisson regression was performed on the imputed data where the self-reported condition was the outcome (Zou, 2004). All results accounted for the stratification, weighting, and clustering effects of the survey data, and corrected for missing data uncertainty.

Statistical analysis and data transformations were performed using Stata version 15 (Stata Corporation, College Station, Texas 2017). Significance was reported at $\alpha<0.05$.

\subsection{Qualitative component}

\subsubsection{Interview participants}

An initial subset of 70 people were selected from the Morwell Adult Survey participants using a random sampling approach, stratified by age and gender. As people 50 years and above were overrepresented in the survey (see Table 1), younger people were oversampled in the extracted sample to ensure a balanced age-distribution of participants. Contact was initiated via post (including a letter and explanatory statement about the study) with follow up contact via email, landline and/or mobile phone. In total, 23 people were unable to be contacted. Additionally, one person was deceased. Upon contact, two people were living interstate and unable to participate, and a further 17 people declined to participate, informing the researchers that they were too busy, or did not have anything new to add to what they had previously reported in the survey. In total, 27 interviews were conducted, with written consent obtained before interviewing commenced. However, in consultation with Monash University Human Research Ethics Committee, one participant was later judged as unable to provide informed consent, due to cognitive competency issues that became evident during the interview, and was excluded. The final sample was 26 interviews.

\subsubsection{Procedure}

The interviews were semi-structured, in-depth, and conducted face-to-face. Interviews followed the same schedule but, depending on the level of detail provided by participants, lasted between 15 and 80 minutes, with most completed within an hour. 
The interviews investigated both the long- and short-term impacts of the event. In line with the mixed methods approach, the qualitative interview schedule was designed to parallel the three subscales of the IES-R. Members of the research team conducted a thematic analysis of the interview transcripts focussed on identifying content in participant responses that corresponded to intrusion, hyperarousal, and avoidance. A process of triangulation was implemented to validate the analysis. Interview transcripts were independently analysed by three members of the research team, with discrepancies then discussed to reach agreement on interpretation.

\section{Results}

\subsection{Demographics}

The quantitative sample exhibited a reasonably balanced weighted proportion of gender, age and marital status between Morwell and Sale participants (Table 1). The main differences in demographics between the two localities related to ethnicity (i.e. country of birth $p<0.001$, language usually spoken at home $\mathrm{p}<0.001$, education $\mathrm{p}<0.001$, and employment $\mathrm{p}=0.039$ ). In both locations, the proportion of people over 50 years of age was more than twice that of people 49 years and under. The significantly lower weighted average IRSAD for Morwell (861.12) participants compared to Sale $(905.86)$ participants $(\mathrm{p}<0.001)$ is consistent with research outlining Morwell as one of the most disadvantaged postcodes in the Latrobe Valley (Vinson, Rawsthorne, Beavis, \& Ericson, 2015). On average, Morwell participants had lived in the Gippsland region for a longer time (37 years) compared to the Sale participants (34 years). 
Table 1. Demographics of Morwell and Sale Adult Survey participants.

\begin{tabular}{|c|c|c|c|c|c|}
\hline \multirow[t]{2}{*}{$\begin{array}{l}\text { Participant } \\
\text { characteristics }\end{array}$} & \multicolumn{2}{|l|}{$\begin{array}{l}\text { Morwell } \\
N=3091\end{array}$} & \multicolumn{2}{|l|}{$\begin{array}{l}\text { Sale } \\
N=960\end{array}$} & \multirow[b]{2}{*}{ p-value } \\
\hline & $\mathrm{n}$ & Weighted $\$$ & $\mathrm{n}$ & Weighted $\$$ & \\
\hline Gender & & & & & 0.121 \\
\hline Male & 1387 & $48 \%$ & 410 & $45 \%$ & \\
\hline Female & 1704 & $52 \%$ & 550 & $55 \%$ & \\
\hline Age group & & & & & 0.557 \\
\hline $18-49$ & 925 & $49 \%$ & 306 & $51 \%$ & \\
\hline $50+$ & 2160 & $51 \%$ & 654 & $49 \%$ & \\
\hline Marital status & & & & & 0.081 \\
\hline Married/de facto & 1851 & $58 \%$ & 611 & $62 \%$ & \\
\hline Not married/de facto & 1211 & $42 \%$ & 333 & $38 \%$ & \\
\hline Country at birth & & & & & $<0.001$ \\
\hline Australia & 2456 & $85 \%$ & 829 & $90 \%$ & \\
\hline Other & 631 & $15 \%$ & 131 & $10 \%$ & \\
\hline $\begin{array}{l}\text { Language usually spoken } \\
\text { in household }\end{array}$ & & & & & $<0.001$ \\
\hline English & 2811 & $93 \%$ & 934 & $98 \%$ & \\
\hline Other & 275 & $7 \%$ & 25 & $2 \%$ & \\
\hline $\begin{array}{l}\text { Aboriginal or Torres Strait } \\
\text { Islander }\end{array}$ & & & & & 0.986 \\
\hline Yes & 30 & $1 \%$ & 8 & $1 \%$ & \\
\hline No & 3020 & $99 \%$ & 947 & $99 \%$ & \\
\hline Education & & & & & $<0.001$ \\
\hline Secondary & 1672 & $51 \%$ & 403 & $39 \%$ & \\
\hline $\begin{array}{l}\text { Certificate/ University } \\
\text { /other Tertiary }\end{array}$ & 1378 & $49 \%$ & 546 & $61 \%$ & \\
\hline Employment & & & & & 0.039 \\
\hline $\begin{array}{l}\text { Paid employment (FT, } \\
\text { PT, } \\
\text { self-employed) }\end{array}$ & 1310 & $51 \%$ & 451 & $56 \%$ & \\
\hline \multirow[t]{2}{*}{ Other } & 1742 & $49 \%$ & 494 & $44 \%$ & \\
\hline & Mean & $\begin{array}{l}\text { Weighted mean } \\
\text { (SE) }\end{array}$ & Mean & $\begin{array}{l}\text { Weighted mean } \\
(\mathrm{SE})\end{array}$ & $p$-value \\
\hline Age & 57.46 & $50.63(0.48)$ & 57.10 & $50.26(0.98)$ & 0.740 \\
\hline Years lived In Gippsland & 41.50 & $37.37(0.40)$ & 38.05 & $34.31(0.78)$ & $<0.001$ \\
\hline IRSAD Score & 861.03 & $861.12(2.85)$ & 906.38 & $905.86(2.54)$ & $<0.001$ \\
\hline
\end{tabular}

${ }^{\$}$ Estimation accounted for sampling stratification, clustering and weighting.

3.2 Psychological health measures 
All IES-R subscales and the K10 had good internal consistency with Cronbach's alpha values ranging from $\alpha=0.92$ (Avoidance and Hyperarousal) to $\alpha=0.97$ (IES-R Total). The statistics for the IES-R, K10 and number of lifetime events are shown in Table 2.

Table 2. IES-R, K10 and number of major stressful events for Morwell and Sale participants.

\begin{tabular}{|c|c|c|c|c|c|}
\hline & Morwell & Sale & & & \\
\hline $\begin{array}{l}\text { Psychological } \\
\text { measure }\end{array}$ & $\begin{array}{l}\mathrm{N}=3091 \\
\text { Weighted } \\
\text { mean (SE) }\end{array}$ & $\begin{array}{l}\mathrm{N}=960 \\
\text { Weighted } \\
\text { mean (SE) }\end{array}$ & Mean diff & $\begin{array}{l}\text { Adj mean diff } \$ \\
(95 \% \mathrm{Cl})\end{array}$ & $p$-value \\
\hline \multicolumn{6}{|l|}{ IES-R } \\
\hline Intrusion (scores 0-32) & $3.94(0.14)$ & $0.63(0.09)$ & 3.31 & $2.68(2.36,3.00)$ & $<0.001$ \\
\hline Avoidance (scores 0-32) & $3.47(0.13)$ & $0.71(0.10)$ & 2.76 & $2.22(1.90,2.53)$ & $<0.001$ \\
\hline Hyperarousal (scores 0-24) & $2.50(0.11)$ & $0.30(0.05)$ & 2.20 & $1.69(1.46,1.92)$ & $<0.001$ \\
\hline Total score (scores $0-88$ ) & $9.87(0.36)$ & $1.66(0.22)$ & 8.20 & $6.53(5.72,7.35)$ & $<0.001$ \\
\hline K10 & $16.66(0.19)$ & $14.06(0.27)$ & 2.60 & $1.69(1.05,2.33)$ & $<0.001$ \\
\hline $\begin{array}{l}\text { Number of lifetime } \\
\text { stressful events }\end{array}$ & $\begin{array}{l}\text { Weighted } \\
\%\end{array}$ & $\begin{array}{l}\text { Weighted } \\
\%\end{array}$ & RRR & $\begin{array}{l}\text { Adj RRR^ } \\
(95 \% \mathrm{Cl}) \\
\end{array}$ & $\mathrm{p}$-value \\
\hline None & $34.3 \%$ & $36.3 \%$ & Reference & Reference & \\
\hline One or two & $37.9 \%$ & $39.6 \%$ & 1.01 & $0.99(0.80,1.23)$ & 0.928 \\
\hline Three or more & $27.7 \%$ & $24.1 \%$ & 1.21 & $1.06(0.83,1.35)$ & 0.657 \\
\hline
\end{tabular}

$\$$ Adjusted for age, gender, education, marital status, IRSAD score, drinking and smoking. Pooled linear regression models accounted for sampling stratification, clustering and weighting.

Compared to Sale participants, Morwell participants scored significantly higher on all the IES-R subscales and the total score, indicating greater mine-fire-related distress in the previous week (Table 2). Morwell participants had significantly higher K10 scores in the past 4 weeks, indicating greater levels of general distress, compared to Sale participants $(p<0.001)$. There was no significant difference in the number of stressful life events between locations, indicating similar exposure to traumatic events prior to the mine fire. While there were group differences on both the IES-R and K10, it should be noted that the majority of participants scored at the lower end on both scales (Figure 1), with most reporting no or low distress. The distributions for the IES-R subscales were very similar to those for the weighted total score. 

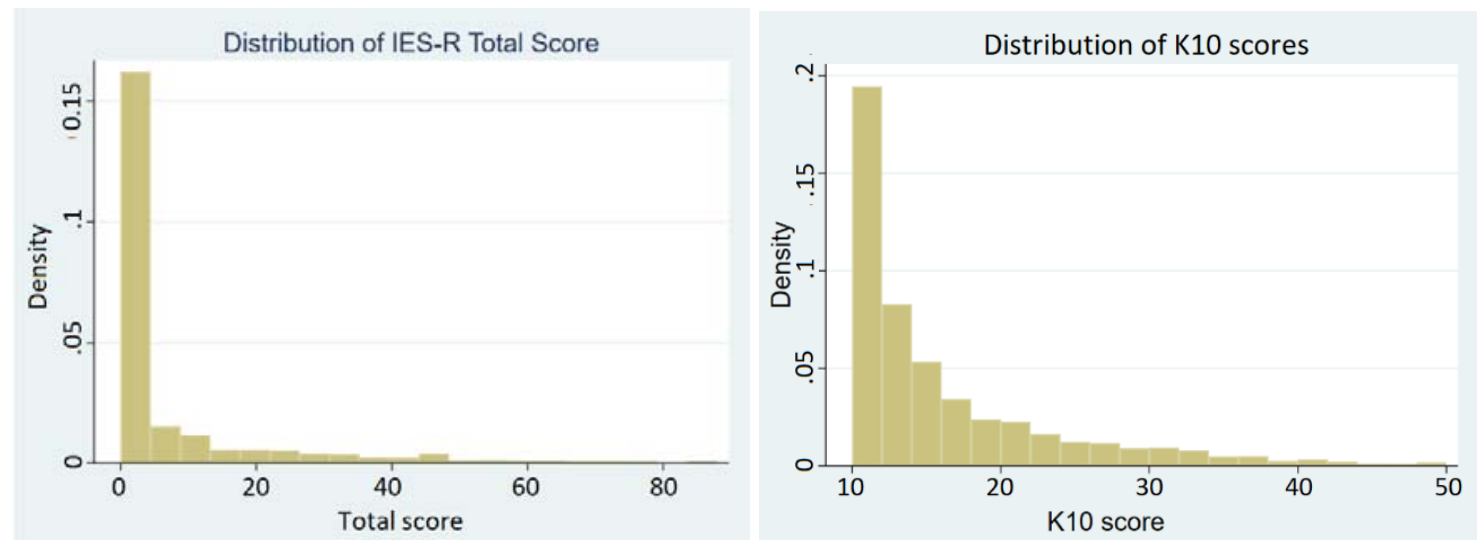

Figure 1. Distribution of IES-R Total and K10 weighted scores.

There were no significant differences between Morwell and Sale in self-reported diagnoses of anxiety, depression, PTSD, or any other mental health condition diagnosed prior to the mine fire event (Table 3). However, following the mine fire, there were indications that Morwell residents were more likely to be diagnosed with PTSD (RR 3.26, 95\% CI 0.87, 12.19, p=0.079). 
Table 3. Self-reported doctor-diagnosed psychological conditions first diagnosed prior to the mine fire (2013 or earlier) or post mine fire (2014 or later).

\begin{tabular}{|c|c|c|c|c|c|c|c|c|c|c|}
\hline \multirow[b]{3}{*}{$\begin{array}{l}\text { Medical } \\
\text { Condition }\end{array}$} & \multicolumn{5}{|c|}{ First diagnosed in 2013 or earlier } & \multicolumn{5}{|c|}{ First diagnosed in 2014 or later } \\
\hline & $\begin{array}{l}\text { Morwell } \\
N=3091\end{array}$ & $\begin{array}{l}\text { Sale } \\
N=3091\end{array}$ & & & & $\begin{array}{l}\text { Morwell } \\
\mathrm{N}=3091\end{array}$ & $\begin{array}{l}\text { Sale } \\
N=3091\end{array}$ & & & \\
\hline & $\begin{array}{l}\text { Weighted } \\
\%\end{array}$ & $\begin{array}{l}\text { Weighted } \\
\%\end{array}$ & $\mathrm{RR}$ & $\begin{array}{l}\text { Adj RR } \\
(95 \% \mathrm{Cl})^{\$}\end{array}$ & $\begin{array}{l}p- \\
\text { value }\end{array}$ & $\begin{array}{l}\text { Weighted } \\
\%\end{array}$ & $\begin{array}{l}\text { Weighted } \\
\%\end{array}$ & $\mathrm{RR}$ & $\begin{array}{l}\text { Adj RR } \\
(95 \% \mathrm{Cl})^{\$}\end{array}$ & $\begin{array}{l}\mathrm{p}- \\
\text { value }\end{array}$ \\
\hline Anxiety & $19.9 \%$ & $17.1 \%$ & 1.16 & $1.04(0.86,1.26)$ & 0.655 & $5.0 \%$ & $3.6 \%$ & 1.37 & $1.28(0.85,1.94)$ & 0.237 \\
\hline Depression & $22.3 \%$ & $21.3 \%$ & 1.05 & $0.89(0.76,1.05)$ & 0.176 & $4.6 \%$ & $3.0 \%$ & 1.56 & $1.36(0.85,2.18)$ & 0.202 \\
\hline PTSD & $4.5 \%$ & $3.2 \%$ & 1.41 & $1.17(0.78,1.75)$ & 0.446 & $1.4 \%$ & $0.4 \%$ & 3.83 & $3.26(0.87,12.19)$ & 0.079 \\
\hline Mental other & $3.2 \%$ & $2.6 \%$ & 1.25 & $0.82(0.49,1.37)$ & 0.447 & $0.8 \%$ & $0.6 \%$ & 1.17 & $0.98(0.39,2.45)$ & 0.971 \\
\hline
\end{tabular}

$\$$ Adjusted for age, gender, education, marital status, IRSAD score, drinking and smoking. Results accounted for sampling stratification, clustering and weighting. 


\subsection{Qualitative Interviews}

Demographic characteristics and average IES-R and K10 scores for interview participants, and for the Adult Survey sample from which they were randomly drawn, are shown in Table 4.

Table 4. Demographic characteristics of survey and interview participants.

\begin{tabular}{|c|c|c|c|}
\hline \multicolumn{2}{|l|}{$\begin{array}{l}\text { Participant demographic } \\
\text { characteristic }\end{array}$} & $\begin{array}{l}\text { Adult Survey } \\
\mathrm{N}=3091 \\
\mathrm{n}(\%)\end{array}$ & \multirow{2}{*}{$\begin{array}{l}\text { Final interview set } \\
\mathrm{N}=26 \\
\mathrm{n}(\%) \\
13(50)\end{array}$} \\
\hline Gender & Male & $1,387(48)$ & \\
\hline & Female & $1,704(52)$ & $13(50)$ \\
\hline \multirow[t]{3}{*}{ Age } & $18-49$ & $925(49)$ & $14(54)$ \\
\hline & $50+$ & $2,160(51)$ & $12(46)$ \\
\hline & Mean (SD) & $51(19.6)$ & $51(13.6)$ \\
\hline \multirow[t]{2}{*}{ Marital status } & Married/de facto & $1,851(58)$ & $12(48)$ \\
\hline & Not married/de facto & $1,211(42)$ & $13(52)$ \\
\hline \multirow{2}{*}{$\begin{array}{l}\text { Highest educational } \\
\text { qualification }\end{array}$} & Secondary & $1,672(51)$ & $12(46)$ \\
\hline & Certificate/University/other Tertiary & $1,378(49)$ & $14(54)$ \\
\hline \multirow[t]{2}{*}{ Employment } & $\begin{array}{l}\text { Paid employment (FT, PT, self- } \\
\text { employed) }\end{array}$ & $1,310(51)$ & $13(50)$ \\
\hline & Other & $1,742(49)$ & $13(50)$ \\
\hline \multirow{3}{*}{$\begin{array}{l}\text { Ever told by doctor or } \\
\text { psychologist }\end{array}$} & Depression & $813(28)$ & $11(42)$ \\
\hline & Anxiety & $747(26)$ & $9(35)$ \\
\hline & Any mental health condition & $1,061(35)$ & $12(46)$ \\
\hline \multirow{4}{*}{$\begin{array}{l}\text { Number of previous } \\
\text { stressful events }\end{array}$} & None & $975(34)$ & $5(19)$ \\
\hline & One or two & $1,200(38)$ & $9(35)$ \\
\hline & Three or more & $865(28)$ & $12(46)$ \\
\hline & & Mean & Mean \\
\hline \multirow{4}{*}{$\begin{array}{l}\text { Impact of Event Scale } \\
\text { - Revised }\end{array}$} & Intrusion & 3.94 & 5.08 \\
\hline & Avoidance & 3.47 & 3.33 \\
\hline & Hyperarousal & 2.50 & 3.28 \\
\hline & Total & 9.87 & 12.00 \\
\hline K10 & & 16.66 & 16.92 \\
\hline
\end{tabular}

Note: Estimations accounted for sampling stratification, clustering and weighting.

During the qualitative interviews, participants were asked about the levels of intrusion, avoidance, and hyperarousal they experienced relating to the smoke event, both at the time of the 
event, and at present. Of the 26 interviewees, 13 indicated they were not impacted at the time of the event nor at the time of the interview. A further nine indicated they were a little to somewhat impacted at the time of the event, but were no longer being impacted. The final four participants indicated they were impacted at the time of the event, and were still impacted at the time of the interview.

Outlined below are interview responses summarised in parallel with the intrusive thoughts, avoidance behaviours, and increased arousal subscales of the IES-R. The initial responses in the subheadings below focus on the time of the event, and the latter at the time of interview.

\subsubsection{Increased arousal}

Those reporting increased arousal at the time of the mine fire indicated they were constantly alert for signs of danger, such as high temperatures or smoke. One participant, who reported a prior diagnosis of PTSD in the interview and survey, was very distressed during the event:

Huge anxiety, woke up, there was smoke, the helicopters were doing the water pickups. I was a mess. There was smoke everywhere. It was the most terrifying time I've ever had. [Friend] used to call me the milkshake maker because when my anxiety got really bad, I started shaking... As a result of the fire, my emotions went really bad. I started cutting myself.

Other participants reported that their sleep and temper were affected during the fire:

It was very hard to sleep because you were scared that if you went to sleep the fire might start.

You just constantly felt like you were on edge as far as the temper went. You try and contain it but yeah.

Some participants reported that the event affected their concentration and made them hypervigilant to danger, for example: 
I think I became more alert. I think it was instinct to become a little bit more alert, try and keep an eye what was happening - survival mode, sort of thing, trying to figure out what was going on.

Three years after the event some participants were still feeling constantly alert and aroused by thoughts of the mine fire. One participant reported that thoughts of the mine fire still kept him awake at night.

Every night I go to sleep I worry about it. Every night I go to bed and I think to myself, geez, am I going to wake up in the morning? That's a horrible feeling.

This participant reported that the event still caused him to feel 'on edge' and lose his temper easily:

I have to hold my tongue not to lose my temper sometimes. I do, yeah. I lose it at the people that love me the most and care about me the most, that's the worst bit.

A participant who had a prior diagnosis of PTSD described the continual feeling of being hypervigilant:

I do have all those symptoms of hyper-alertness, looking out: what's my exit strategy here? Very, very alert, always thinking security wise. You know before we go to bed we check the doors three or four times.

\subsubsection{Intrusive thoughts}

Some participants found the fire and smoke intruding into their thoughts and memories, with one participant describing thoughts about the fire returning on hot days:

And so you get those hot days again, you know the winds right and you stand out on the balcony, you remember straight back, you just have this vision.

Another participant, a member of the Country Fire Authority (CFA) who was on-call during the fire, described the constant repetition of thoughts about the fire during that time:

So you replay it constantly for the next you know three, four, five weeks and you miss bits but then you fill gaps in later on, with oh now I did that and did this. 
Participants who scored highly on the IES-R continued to experience intrusive thoughts about the fire after the event. One woman reported that a few months after the fire ended a particular smell triggered intrusive thoughts:

Probably about three months later, some farmer must have sprayed fertiliser or something... and then it was just the whole panic again, thinking, oh, I just cannot live through this again.

Some participants were still experiencing intrusive thoughts at the time of the interview, three years after the event. In some cases, the smell of smoke still triggered intense thoughts of the fire:

If they're burning off and I smell the smoke, I sort of get a little bit of a panic attack. Another participant said that he continued to dwell on the event daily:

Every night I go to sleep I worry about it, I think about it.

\subsubsection{Avoidance behaviour}

Some participants reported using avoidance techniques at the time of the fire to cope with their circumstances and emotions. These participants were continuing to make efforts to avoid thoughts of the mine fire and situations that might trigger memories. One participant said that sometimes he physically removed himself from reminders of the mine fire:

Sometimes I've just got to get up and walk away, think about something else, get my mind onto something else.

Another participant turned her mind away from thoughts or reminders of the mine fire in the media:

I just try and turn off. How I deal with it is, oh, Christ, crock of shit, and just throw it... I don't even engage in reading it, because I know it will just get my blood pressure up. I'm better off not even reading it.

\subsubsection{Impacts upon mental health}

Some participants with a self-reported prior diagnosis of mental illness indicated that the fire exacerbated their symptoms. One man felt that his depressive symptoms became worse during the fire: 
I've got clinical depression which I had but the depression's got worse because when you go through all this stuff, it gets worse, it doesn't do better.

Another member of the CFA reported that he experienced an increase in pre-existing posttraumatic stress symptoms during and after the Hazelwood mine fire

I've had PTSD for 20 years. From this fire and two thousand other fires I went to.

Flashbacks, not just of this fire.... [The Hazelwood fire] contributes because it triggers a certain taste, a certain memory, a certain sight. Bang you're having this experience in your head.

\subsection{Concordance between qualitative and quantitative data}

As described in the Methods section, the IES-R measure was used to connect the qualitative and quantitative components of the research program, providing an opportunity to see whether there was consistency in how participants responded in terms of event-related distress.

Six interview participants were identified as of clinical concern for PTSD with IES-R scores between 28 and 63 that exceeded the cut-off of 24 indicating possible risk (Asukai et al., 2002). Four of these participants indicated they experienced heightened arousal, intrusive thoughts and avoidance behaviour at the time of the fire and were still experiencing some of these symptoms at the time of interview, three years after the event. The remaining two participants indicated in the interview that they were somewhat (although not extremely) impacted by the fire at the time. One reported being concerned about her partner's health while the other felt very lethargic. One participant who scored 13 on the IES-R indicated in the interview experiencing increased arousal, intrusive thoughts and avoidance behaviours to some degree. Another participant who reported similar concerns in the interview had not completed the IES-R section of the survey - possibly evidence of avoidance behaviour.

\section{Discussion}

More than two years after the Hazelwood fire Morwell residents were registering a significantly higher distress associated with the event (total IES-R and all subscales) and higher 
general mental distress (K10) compared to a control group of participants from Sale. They were also over three times more likely than Sale participants to report a diagnosis of posttraumatic stress disorder since the mine fire event, although the numbers of people affected were very small. While there were differences following the event, there were no differences in mental health conditions between Morwell and Sale prior to the mine fire, nor difference in number of lifetime stressful life events, indicating that the Sale community was a suitable comparison community for the purposes of the current analyses.

The average Morwell IES-R score of ten was below any of the proposed thresholds for PTSD (Asukai et al., 2002; Creamer et al., 2003; Morina et al., 2010) and lower than the mean of 18 reported for a potentially comparable previous smoke (Ho et al., 2014). The Ho et al. study captured the impact of a smoke haze event as it occurred whereas the current study assessed impacts some two years afterwards, which may explain the lesser impacts reported here.

In addition to higher event-related distress on the IES-R, it is telling that Morwell participants reported higher general distress on the K10, which was not specifically tagged specifically to the smoke event. The weighted average score of 17 for Morwell residents was over the published ABS cut-off of 16 for moderate distress (Australian Bureau of Statistics, 2012), with individual scores ranging from 10 to 50 (unweighted). This finding aligns with published associations between smoke exposure and physical effects (e.g. Reid et al., 2016) which have highlighted the relationship between short-term and chronic ill health and potential later psychological distress.

Another finding from the study is that the rate of PTSD diagnosis in Morwell may have increased subsequent to the mine fire. While there was a threefold increase for Morwell residents, this difference was just below the threshold of significance $(\mathrm{p}=0.079)$ and was based on very small numbers $(0.4 \%$ in Sale vs $1.4 \%$ in Morwell). It is likely that this increase in Morwell may be from higher-risk residents of the town. McFarlane and Williams (2012) suggest that it is "important to have an overview of the wider panoply of risks and effects..." (p. 4), particularly with reference to 
things such as pre-existing mental health conditions, traumatic exposures or social problems. Further analysis would be beneficial to examine the relationships between the higher PTSD and K10 scores and other potentially predetermining factors to identify the most vulnerable subgroups. While it is plausible that the event continued to generate community-wide distress some two years later, an alternative explanation is that high scoring in a subgroup of vulnerable members of the community brought up the overall average (as seen in Figure 1). It is possible that for some highscoring Morwell residents, the impact of previous mental health disorders or traumatic exposures underlies their appraisal of the Hazelwood event over two years later. "Appraisals are conscious or unconscious judgements about the nature of the environment and one's ability to respond to it" (Bakal, 1992, pp.72). Hence, prior psychosocial problems (such as existing mental health diagnoses) in a subgroup of the community may be an important factor contributing to the higher level of event-related distress reported in this study.

This important subgroup of vulnerable Morwell residents may also be represented within the qualitative interviews. The interview findings support the argument that this impact may have been greater for people with prior mental health concerns, with one man's depressive symptoms worsening during the fire and another's PTSD heightened during the event. Again, this finding aligns with previously published research showing that those with prior psychosocial problems may be more impacted by community-wide critical events (Neria, Nandi, \& Galea, 2008; Norris, Friedman, \& Watson, 2002)

The interviews with Morwell participants also highlighted the same spread of responses to the event evident in the scale scores, with six participants strongly impacted at the time of the survey, and four remaining impacted three years post-event. Although half of the interview participants reported no impact at the time of the event and most reported no impact three years after, a long-term impact was reported for approximately $15 \%$ of the interview sample, which is consistent with previous research (Bryant et al., 2014, i.e. 15.6\%). 
In the qualitative interviews, participants most commonly reported increased levels of arousal and intrusive thoughts. At the time of the fire, they were constantly alert to danger and reported that normal functioning (e.g. sleep; emotions) was disrupted. This is consistent with bushfire research showing higher fire-related PTSD in highly impacted communities (Bryant et al., 2014). Intrusive thoughts were triggered by stimuli such as the smell of smoke and fertilisers. This finding is consistent with previous research showing intrusive thoughts are the most commonly reported symptom post-disaster (Durham, McCammon, \& Allison Jr, 1985). In interviews, participants talked less about avoidance behaviours during and following the event.

This study has recognised limitations. The lower response of younger adults compared to those aged 50 years and older on the Adult Survey, as well as recruitment of residents from more advantaged groups, could have also reduced understanding of the impacts for younger and more disadvantaged groups. In-addition, using self-reported mental health history, and collapsing age into two categories (i.e. 18-49 and 50+) may have reduced the precision of these measures. In addition, the small random sample of adults from Morwell for the qualitative interviews may have restricted the range of possible responses.

In conclusion, this study highlights the potential for pollution events to increase psychological distress in those who are most exposed. The mixed methods analysis shows that there is considerable individual differences in how people respond to such events, with most unlikely to have long-term impacts. In addition, those with pre-existing mental health conditions may be more likely to have ongoing concerns as a result of the event, or to attribute their existing concerns to the event. Whether or not the Hazelwood mine fire directly resulted in increased distress or changed how people attributed the causes for their existing distress, the consistency between the IES-R, K10, and self-reported mental health diagnoses following the event indicates that it had an adverse effect on psychological wellbeing in the Morwell community. Importantly, the current study shows that a smoke event can have a distressing impact on a community in the absence of clear physical damage such as mortality or major property damage. This has important implications for the future handling 
of large-scale pollution events. While this study focused on community-wide impacts, additional research with those who reported continued impact, along with consideration of other factors that might contribute to their increase risk, is recommended. This study aids in equipping health professionals and service providers with a better understanding of the psychological impacts of smoke events, and the potential for some groups (such as those with prior mental health concerns) to be more at risk, so that they can better appreciate and manage psychological distress in adults, and limit resultant mental health and stress-related complications.

\section{Acknowledgements}

We would like to acknowledge the contribution of the broader Hazelwood Health Study team responsible for the collection of the quantitative data as part of the Adult Survey. We would also like to acknowledge the contribution of study participants in both the quantitative and qualitative components.

\section{Funding}

This study was funded by the Victorian Department of Health and Human Services. The paper presents the views of the authors and does not represent the views of the Department.

\section{Declarations of interest}

None. 


\section{References}

Abramson, M., Blackman, J., Carroll, M., Dimitriadis, C., Del Monaco, A., Dennekamp, M., .. . Walker, J. (2017). Hazelwood Health Study Adult Survey: Volume 1 Comparison of Morwell and Sale. Retrieved from:

http://hazelwoodhealthstudy.org.au/wpcontent/uploads/2017/01/HHSAdultSurveyVol1_Rep ort_v1.1-compressed.pdf

American Psychiatric Association. (2013). Diagnostic and statistical manual of mental disorders (5th ed.). Arlington, VA: American Psychiatric Publishing.

Asukai, N., Kato, H., Kawamura, N., Kim, Y., Yamamoto, K., Kishimoto, J., . . Nishizono-Maher, A. (2002). Reliability and validity of the Japanese-language version of the impact of event scale-revised (Ies-RJ): Four studies of different traumatic events. The Journal of Nervous and Mental Disease, 190(3), 175-182. doi:10.1097/00005053-200203000-00006

Australian Bureau of Statistics (2012). Information paper: Use of the Kessler Psychological Distress Scale in ABS health surveys, Australia, 2007-08 (Cat. No. 4817.0.55.001). Retrieved from: http://www.abs.gov.au/ausstats/abs@.nsf/Lookup/4817.0.55.001Chapter 92007-08.

Australian Bureau of Statistics (2013). Census of population and housing: Socio-Economic Indexes for Areas (SEIFA), Australia, 2011 (Cat. No. 2033.0.55.001). Retrieved from: http://www.abs.gov.au/ausstats/abs@.nsf/Lookup/2033.0.55.001main+features100042011

Bakal, D. A. (1992). Psychology and health. New York, NY: Springer Publishing Co.

Baxter, J., Eyles, J., \& Willms, D. (1992). The Hagersville tire fire: Interpreting risk through a qualitative research design. Qualitative Health Research, 2(2), 208-237. doi:10.1177/104973239200200206

Bryant, R. A., Waters, E., Gibbs, L., Gallagher, H. C., Pattison, P., Lusher, D., . . Forbes, D. (2014). Psychological outcomes following the Victorian Black Saturday bushfires. 
Australian \& New Zealand Journal of Psychiatry, 48(7), 634-643.

doi:10.1177/0004867414534476

Creamer, M., Bell, R., \& Failla, S. (2003). Psychometric properties of the Impact of Event ScaleRevised. Behaviour Research and Therapy, 41(12), 1489-1496.

doi:10.1016/j.brat.2003.07.010

Cresswell, J. W. (2014). Research design: Qualitative, quantitative, and mixed methods approaches (4th ed.). Thousand Oaks, CA: SAGE.

Durham, T. W., McCammon, S. L., \& Allison Jr, E. J. (1985). The psychological impact of disaster on rescue personnel. Annals of Emergency Medicine, 14(7), 664-668. doi:10.1016/S01960644(85)80884-2

Emmerson, K., Reisen, F., Luhar, A., Williamson, G., \& Cope, M. (2016). Air quality modelling of smoke exposure from the Hazelwood mine fire. CSIRO Australia. doi:10.4225/08/594eb6e7304dc

Ho, R. C., Zhang, M. W., Ho, C. S., Pan, F., Lu, Y., \& Sharma, V. K. (2014). Impact of 2013 south Asian haze crisis: Study of physical and psychological symptoms and perceived dangerousness of pollution level. BMC Psychiatry, 14, 81. doi:10.1186/1471-244X-14-81

Kessler, R. C., Barker, P. R., Colpe, L. J., Epstein, J. F., Gfroerer, J. C., Hiripi, E., . . Walters, E. E. (2003). Screening for serious mental illness in the general population. Archives of General Psychiatry, 60(2), 184-189. doi:10.1001/archpsyc.60.2.184

Kessler, R. C., \& Mroczek, D. (1994). Final versions of our non-specific psychological distress scale. Memo dated March, 10, 1994.

Little, R. J. (1988). A test of missing completely at random for multivariate data with missing values. Journal of the American Statistical Association, 83(404), 1198-1202. doi:10.1080/01621459.1988.10478722

Little, R. J. (1995). Modeling the drop-out mechanism in repeated-measures studies. Journal of the American Statistical Association, 90(431), 1112-1121. doi:10.2307/2291350 
McFarlane, A. C. (1988). The phenomenology of posttraumatic stress disorders following a natural disaster. The Journal of Nervous and Mental Disease, 176, 22-29. doi:10.1097/00005053198801000-00003

McFarlane, A. C., Clayer, J., \& Bookless, C. (1997). Psychiatric morbidity following a natural disaster: An Australian bushfire. Social Psychiatry and Psychiatric Epidemiology, 32(5), 261-268. doi:10.1007/BF00789038

McFarlane, A. C., \& Williams, R. (2012). Mental health services required after disasters: Learning from the lasting effects of disasters. Depression Research and Treatment, 2012. doi:10.1155/2012/970194

Melody, S. M., \& Johnston, F. H. (2015). Coal mine fires and human health: What do we know?. International Journal of Coal Geology, 152, 1-14. doi:10.1016/j.coal.2015.11.001

Morina, N., Bohme, H. F., Ajdukovic, D., Bogic, M., Franciskovic, T., Galeazzi, G. M., .. . Priebe, S. (2010). The structure of post-traumatic stress symptoms in survivors of war: Confirmatory factor analyses of the Impact of Event Scale-Revised. Journal of Anxiety Disorders, 24(6), 606-611. doi:10.1016/j.janxdis.2010.04.001

Neria, Y., Nandi, A., \& Galea, S. (2008). Post-traumatic stress disorder following disasters: A systematic review. Psychological Medicine, 38(4), 467-480. doi:10.1017/S0033291707001353

Norris, F. H., Friedman, M. J., \& Watson, P. J. (2002). 60,000 disaster victims speak: Part II. Summary and implications of the disaster mental health research. Psychiatry: Interpersonal and Biological Processes, 65(3), 240-260. doi:10.1521/psyc.65.3.240.20169

Rao, J. N., \& Scott, A. J. (1981). The analysis of categorical data from complex sample surveys: Chi-squared tests for goodness of fit and independence in two-way tables. Journal of the American Statistical Association, 76(374), 221-230. doi:10.1080/01621459.1981.10477633 
Rao, J. N., \& Scott, A. J. (1984). On chi-squared tests for multiway contingency tables with cell proportions estimated from survey data. The Annals of Statistics, 46-60. doi:10.1214/aos/1176346391

Reid, C. E., Brauer, M., Johnston, F. H., Jerrett, M., Balmes, J. R., \& Elliott, C. T. (2016). Critical review of health impacts of wildfire smoke exposure. Environmental Health Perspectives, 124(9), 1334. doi: 10.1289/ehp.1409277

Robins, L. N., Wing, J., Wittchen, H. U., Helzer, J. E., Babor, T. F., Burke, J., . . Regier, D. A. (1988). The Composite International Diagnostic Interview: An epidemiologic instrument suitable for use in conjunction with different diagnostic systems and in different cultures. Archives of General Psychiatry, 45(12), 1069-1077.

doi:10.1001/archpsyc.1988.01800360017003

Royston, P., \& White, I. R. (2011). Multiple imputation by chained equations (MICE): Implementation in Stata. Journal of Statistical Software, 45(4), 1-20. doi:10.18637/jss.v045.i04

Rubin, D.E. (1987). Multiple imputation for nonresponse in surveys. New York: Wiley.

Teague, B., Catford, J., \& Petering, S. (2014). Hazelwood Mine Fire Inquiry report. Hazlwood Mine Fire Inquiry. Retrieved from: http://report.hazelwoodinquiry.vic.gov.au/

Vinson, T., Rawsthorne, M., Beavis, A., \& Ericson, M. (2015). Dropping off the edge 2015:

Persistent communal disadvantage in Australia. Jesuit Social Services / Catholic Social Services Australia. Retrieved from: http://k46cs13u1432b9asz49wnhcx-wpengine.netdnassl.com/wp-content/uploads/0001_dote_2015.pdf

Weiss, D., \& Marmar, C. (1997). The Impact of Event Scale-Revised. In J. P. Wilson and T. M. Keane (Eds.). Assessing psychological trauma and PT-SD. New York, NY: Guliford Press. Wolter, K. (2007). Introduction to variance estimation. New York, NY: Springer Science \& Business Media. 
Wood, P., Duffy, M., Yell, S., Morrissey, B., Whyte, S., Walker, L., . . Maybery, D. (2015). Coal mine fire initial impact on community health and wellbeing summary report. Churchill, Victoria: Federation University Australia.

Zou, G. (2004). A modified poisson regression approach to prospective studies with binary data. American Journal of Epidemiology, 159(7), 702-706. doi:10.1093/aje/kwh090 